\title{
Social media for the growth of a scientific community: the case of the Italian Young Crystallographers Group
}

\author{
Paolo P. Mazzeo \\ Univerity of Parma, Parco Area delle Scienze 17/A, 43124 Parma (IT) \\ paolopio.mazzeo@unipr.it
}

The Italian Young Crystallographers (trad. Giovani Cristallografi Italiani aka GCI) group was formally established in 2018 driven by the need of having a common place for students and young researchers to share their experiences and develop a common sense of affiliation to the main national association.

However, the possibility to meet each other at conferences and congresses are rather modest even without the well-known pandemic constrains, so, we decided to use social media to share information among the community on a regular basis. The social media platforms soon became a virtual place where young generation of crystallographers are informed of job vacancies around the world, promote their latest research and enrich their crystallographic knowledge.

As a consequence, the number of younger scientists associated increased significantly in the last two years and the GCI, fully supported by the national crystallographic association, plays a central role in all the scientific activities organized locally and at the national level.

I here report the strategies used to develop the social media platforms and the initiative promoted by GCI to engage young researchers in crystallography.

Keywords: Social Media; Young Crystallographers; Scientific community growth.

The Italian Young Crystallographers Group (GCI), Dr. Giorgia Confolonieri and Dr. Marta Morana are warmly acknowledged. The Italian Crystallography Association (AIC) is also acknowledged for the support on the activity proposed by GCI. 